\title{
KAJIAN ETIKA LINGKUNGAN KEPESISIRAN TUBAN BERDASARKAN NILAI WILAYAH KEPESISIRAN
}

\author{
Dini Atikawati ${ }^{1 *}$, Totok Gunawan²), Sunarto2) \\ ${ }^{1)}$ Program Doktor Ilmu Lingkungan, Sekolah Pascasarjana, Universitas Gadjah Mada \\ ${ }^{2)}$ Fakultas Geografi, Universitas Gadjah Mada \\ *Email: dini_atikawati@yahoo.co.id.
}

\section{ABSTRACT \\ STUDY OF THE COASTAL ENVIRONMENTAL ETHICS OF TUBAN BASED ON COASTAL AREA VALUES}

Tuban coastal area is very rich in natural resources and environmental services. Along the coastal area there are many infrastructures and activity centers. Various forms of existing activities and uses have negative impact, so Tuban coastal area is vulnerable to environmental damage. Prevention efforts that can be done are through the study of environmental ethics. This research aims to study the value of Tuban coastal area, assess the environmental ethics of community in Tuban coastal area, and formulate the coastal environmental ethics of Tuban based on coastal area values. The data werecollected from observation, field portraits, and interviews. Then the data were analysedby scoring and descriptive. The results showed that the highest coastal area values in Karangagung, Panyuran, Sukolilo and Kutorejo is economic value. The highest environmental ethics values is in Kutorejo, while the lowest is in Karangagung. Coastal environmental ethics of Tuban are formulated based on eleven coastal area values that contain of behaviors that should be carried out by coastal communities so that the sustainability of Tuban coastal area can be maintained.

Keywords: environmental ethics, coastal area values, management, attitudes, coastal area

\section{PENDAHULUAN}

Wilayah kepesisiran merupakan wilayah yang sangat berarti bagi kehidupan manusia. Wilayah transisi antara ekosistem darat dan laut ini memiliki keunikan ekosistem dan ciri khas dalam kondisi fisik, sosial, dan ekonomi sehingga kaya akan sumberdaya alam dan jasa-jasa lingkungan (Clark, 1996; Hartomo, 2004). Selain itu, wilayah kepesisiran merupakan pemandangan alam yang indah, yang dapat dimanfaatkan untuk kesejahteraan manusia dan penting sebagai pelayaran (Pagoray, 2003).

Sumberdaya pesisir terdiri dari unsurunsur hayati dan nonhayati yang terdapat di wilayah laut. Unsur hayati terdiri atas ikan, mangrove, terumbu karang, padang lamun, dan biota lain. Unsur nonhayati terdiri dari sumberdaya di lahan pesisir, permukaan air, di dalam air, dan di dasar laut, seperti minyak bumi dan gas, pasir kuarsa, timah (Idris, 2001).

Berbagai macam bentuk aktivitas dan pemanfaatan di wilayah kepesisiran menimbulkan dampak negatif. Dewasa ini, kondisi wilayah kepesisiran semakin mengkhawatirkan. Hampir di sepanjang pantai utara Jawa ekosistem terumbu karang dan mangrove atau tanaman pantai lainnya sudah rusak, sehingga hempasan ombak menerjang rumah-rumah penduduk dan jalan raya. Hal ini tentu akan mengancam kehidupan masyarakat pesisir, seperti yang terjadi di wilayah kepesisiran Tuban.

Di sepanjang wilayah kepesisiran Tuban banyak terdapat infrastruktur dan pusat-pusat kegiatan, antara lain jalan arteri primer Pantura yang menghubungkan Jawa TimurJawa Barat, pelabuhan, pergudangan, industri, permukiman, dan pariwisata. Kawasan pesisir tersebut direncanakan sebagai kawasan Industri Terpadu Jawa Timur dengan adanya rencana pembangunan pelabuhan, 
pengembangan kota perikanan dan pelabuhan, serta pengembangan kawasan minapolitan. Sebagai pusat kegiatan dan ekonomi, wilayah kepesisiran Tuban rentan terjadi kerusakan lingkungan.

Berdasarkan fenomena tersebut, perlu dilakukan upaya penanggulangan agar dampak negatif yang ditimbulkan oleh berbagai macam pemanfaatan di wilayah kepesisiran dapat diminimalkan. Upaya tersebut dapat dilakukan melalui kajian etika lingkungan. Etika lingkungan sangat berpengaruh terhadap cara pikir dan cara tindak manusia dalam menanggapi lingkungan (Anonim, 2014).Munculnya masalah lingkungan adalah masalah moral dan persoalan perilaku manusia (Keraf, 2010; Wiryono, 2012). Etika lingkungan merupakan petunjuk dalam mengusahakan terwujudnya moral lingkungan. Konsep pengelolaan sumberdaya alam yang bertanggung jawab merupakan langkah baik dalam mengatasi kerusakan lingkungan. Pengelolaan sumberdaya alam yang bertanggung jawab merupakan proses pengelolaan yang sesuai dengan kebutuhan saat ini tanpa mengurangi kebutuhan generasi yang akan datang (Soemiarno, dkk., 2010).

Penelitianini bertujuan untuk, mengkaji nilai wilayah kepesisiran Tuban, menilai etika lingkungan masyarakat di wilayah kepesisiran Tuban dan merumuskan etika lingkungan kepesisiran Tuban berdasarkan nilai wilayah kepesisiran.

\section{METODOLOGI}

\subsection{Lokasi dan Waktu Penelitian}

Penelitian ini dilakukan di empat desa/kelurahan pesisir yang terdapat di Kabupaten Tuban, yaitu Desa Karangagung dan Panyuran di Kecamatan Palang serta Kelurahan Sukolilo dan Kutorejo di Kecamatan Tuban pada bulan Januari sampai dengan Maret 2017.

\subsection{Prosedur Penelitian}

Pengumpulan data diperoleh dengan observasi, potret lapangan, dan wawancara. Observasi dilakukan dengan mengamati secara langsung fenomena yang terjadi di lapangan. Setelah itu, dilakukan potret lapangan untuk mendokumentasikan fenomena tersebut. Wawancara dilakukan dengan menggunakan instrumen non tes berupa panduan penilaian wilayah kepesisiran dan etika lingkungan. Instrumen ini menggunakan skala pengukuran berupa skala sikap. Skala sikap digunakan untuk mengukur sikap, pendapat, dan persepsi seseorang tentang fenomena sosial (Widoyoko, 2006).

Pengambilan sampel responden untuk masing-masing desa/kelurahan sejumlah 35 orang yang terdiri dari 30 orang masyarakat pesisir dan lima orang perangkat desa/kelurahan. Terdapat empat desa/kelurahan sampel, sehingga jumlah responden sebanyak 140 orang.

Analisis data yang digunakan dalam penelitian ini yaitu analisis skoring dan deskriptif. Skoring yang digunakan mengacu pada skala Likert (Widoyoko,2006; Azwar,2009). Peneliti menggunakan skala Likert model empat pilihan (skala empat). Skala disusun dalam bentuk suatu pernyataan dan diikuti oleh pilihan sikap yang menunjukkan tingkatan. Pemilihan skala empat dimaksudkan agar tidak ada peluang bagi responden untuk bersikap netral sehingga memaksa responden untuk menentukan sikap terhadap fenomena sosial yang dinyatakan dalam instrumen.

Tabel 1. Skoring Skala Likert

\begin{tabular}{llccc}
\hline & \multirow{2}{*}{ Kategori Sikap } & \multicolumn{2}{c}{ Skor } & \multirow{2}{*}{ Klasifikasi Skor } \\
\cline { 3 - 4 } & & Positif & Negatif & \\
\hline SS (sangat setuju) & SS (sangat senang) & 4 & 1 & $>113,75-140$ \\
S (setuju) & S (senang) & 3 & 2 & $>87,50-113,75$ \\
TS (tidak setuju) & TS (tidak senang) & 2 & 3 & $>61,25-87,50$ \\
STS (sangat tidak setuju) & STS (sangat tidak senang) & 1 & 4 & $35-61,25$ \\
\hline
\end{tabular}




\section{HASIL DAN PEMBAHASAN}

\subsection{Nilai Wilayah Kepesisiran Tuban}

Nilai-nilai potensial wilayah kepesisiran meliputi estetika, ekologis, rekreasi, edukasi, moral/etis, sejarah/budaya, pengobatan,

\subsubsection{Nilai Wilayah Kepesisiran Desa Karangagung}

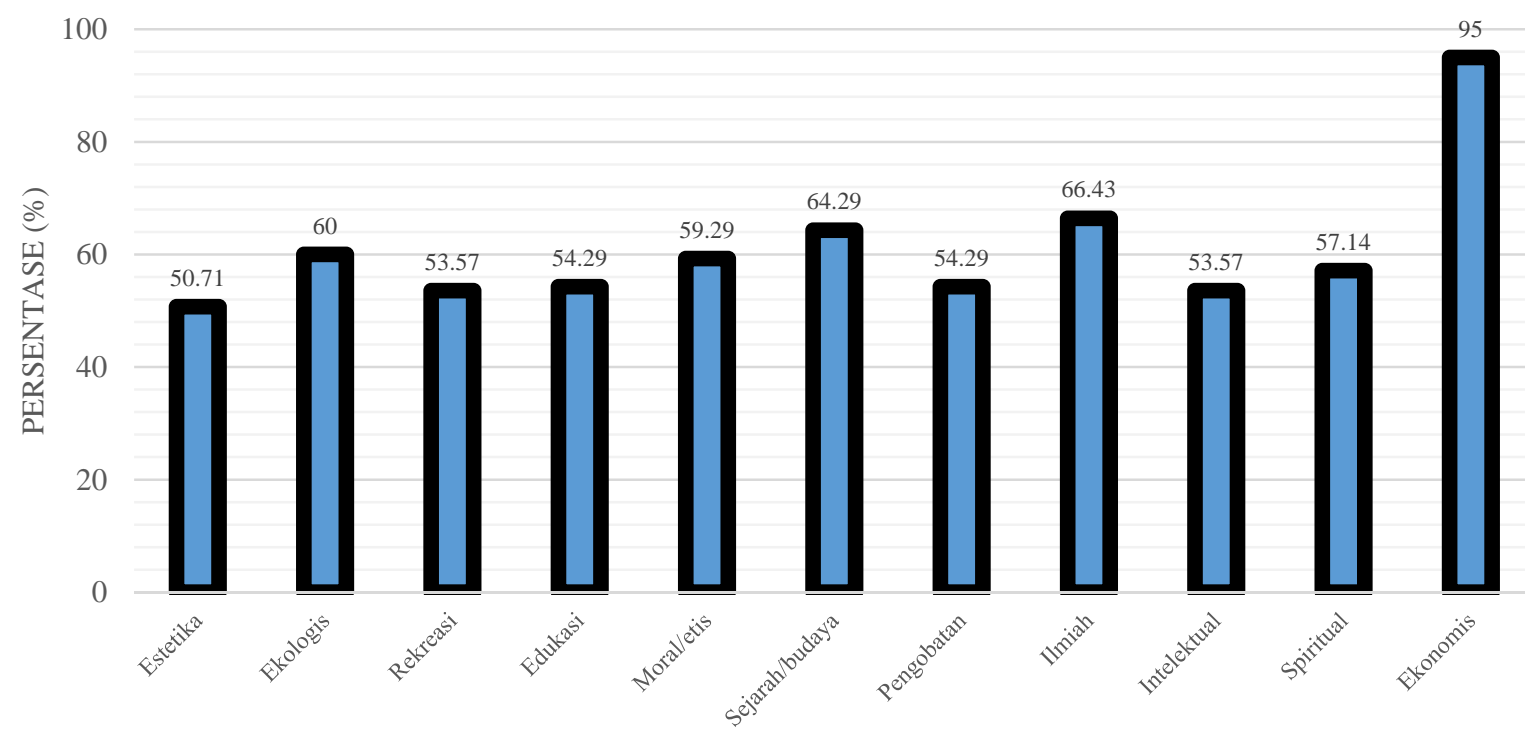

Gambar 1.

Nilai Wilayah Kepesisiran Karangagung

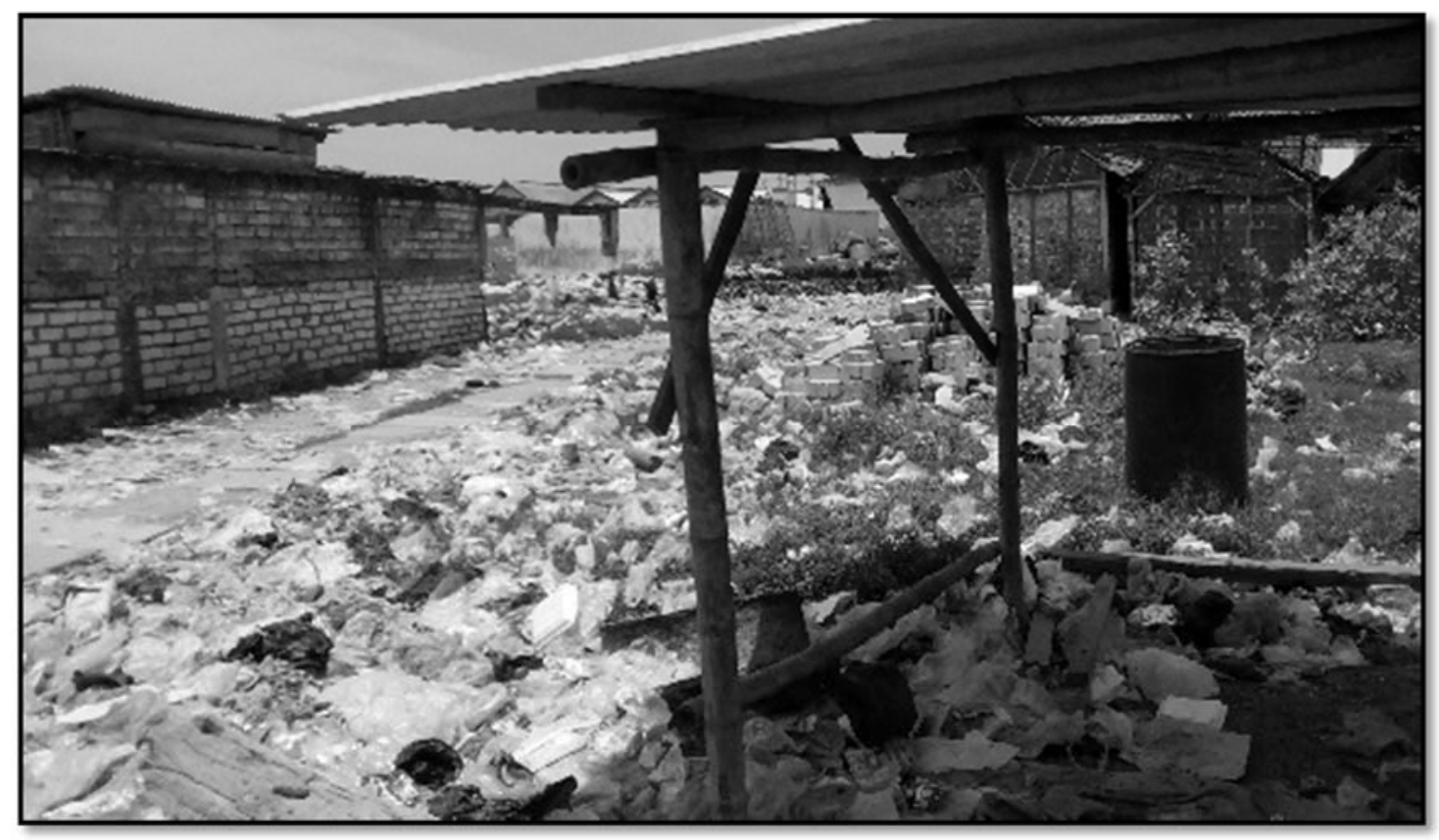

Gambar 2.

Sampah berserakan terdapat di jalan, lahan kosong, dan bangunan sekitar TPI

Berdasarkan grafik di atas, diketahui bahwa nilai wilayah kepesisiran Karangagung ilmiah, intelektual, spiritual, dan ekonomis. Penentuan nilai-nilai potensial ini didasarkan pada klasifikasi Manning, dkk. (1999). Berdasarkan hasil penelitian, diperoleh nilai wilayah kepesisiran Tuban sebagai berikut. 
nilai estetika. Hasil pengamatan di lapangan, wilayah kepesisiran Karangagung dimanfaatkan sebagai Tempat Pelelangan
Ikan dan permukiman. Terdapat banyak sekali sampah di sekitar TPI.

\subsubsection{Nilai Wilayah Kepesisiran Desa \\ Panyuran}

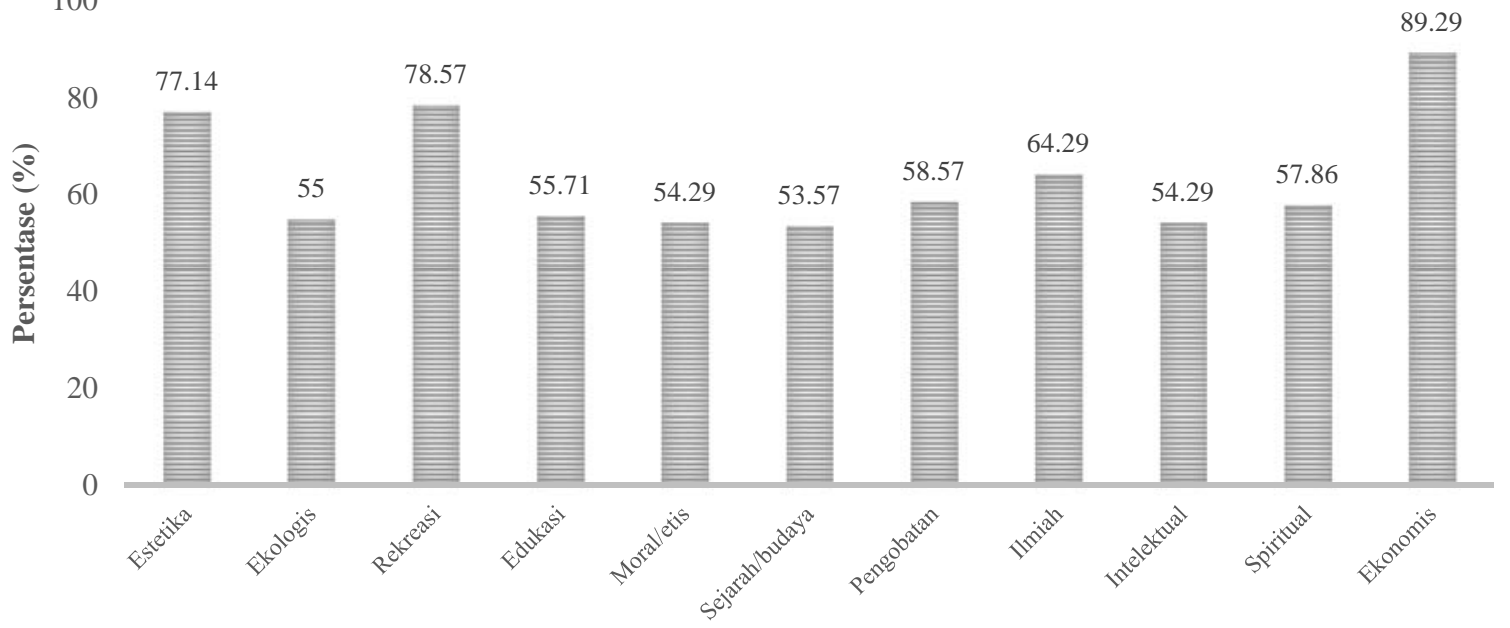

Gambar 3.

Nilai Wilayah Kepesisiran Panyuran

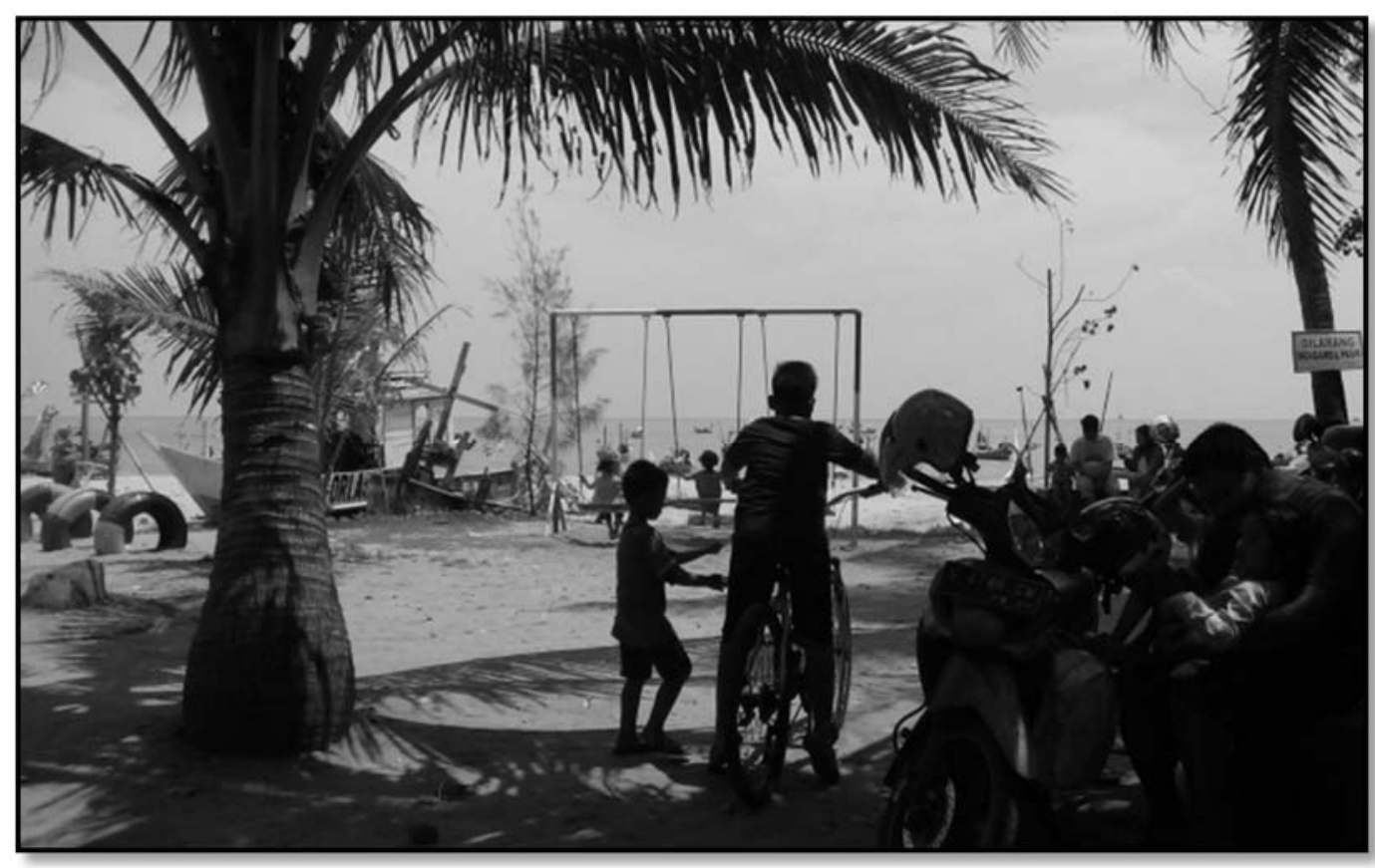

Gambar 4.

Wisata Pantai Kelapa di Desa Panyuran

Berdasarkan grafik di atas, diketahui bahwa nilai wilayah kepesisiran Panyuran yang paling tinggi $(89,29 \%)$ yaitu nilai ekonomis dan nilai yang paling rendah
(53,57\%) yaitu nilai sejarah/budaya. Hasil pengamatan di lapangan, wilayah kepesisiran Panyuran dimanfaatkan sebagai wisata pantai dan permukiman. 


\subsubsection{Nilai Wilayah Kepesisiran \\ Kelurahan Sukolilo}

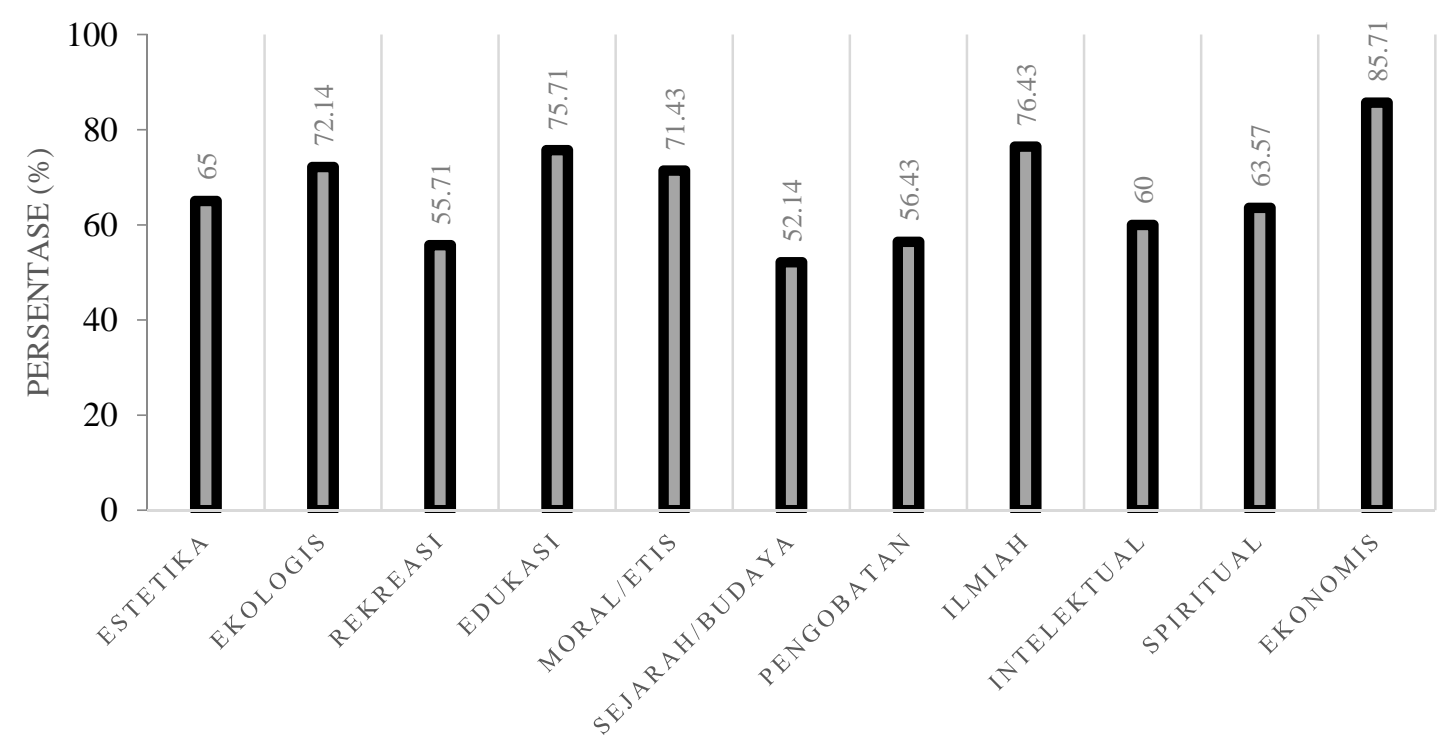

Gambar 5.

Nilai Wilayah Kepesisiran Sukolilo

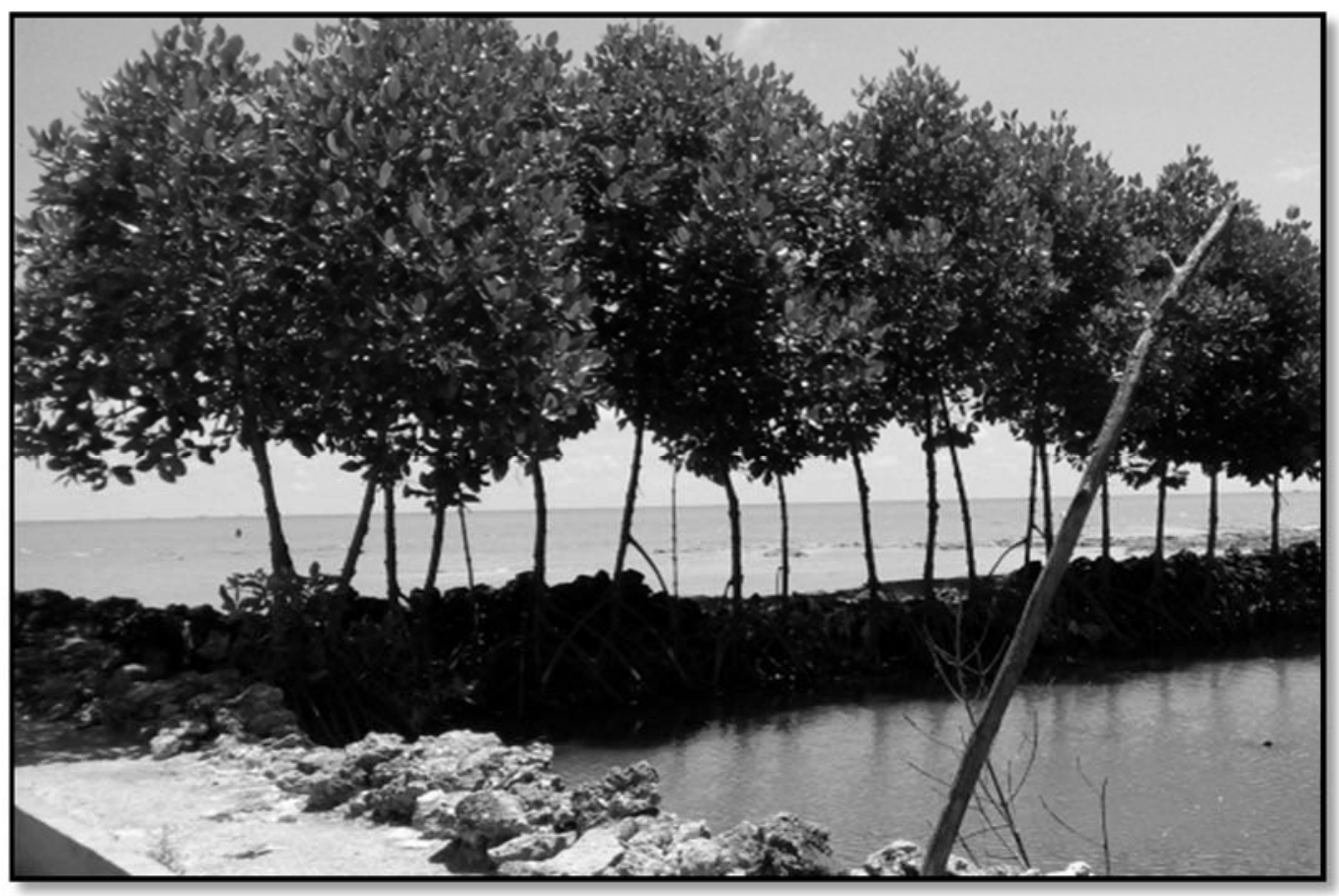

Gambar 6.

Budidaya mangrove yang terdapat di pantai Sukolilo

Berdasarkan grafik di atas, diketahui bahwa nilai wilayah kepesisiran Sukolilo yang paling tinggi (85,71\%) yaitu nilai ekonomis dan nilai yang paling rendah
(52,14\%) yaitu nilai sejarah/budaya. Hasil pengamatan di lapangan, wilayah kepesisiran Panyuran dimanfaatkan sebagai permukiman, budidaya mangrove, dan cemara. 


\subsubsection{Nilai Wilayah Kepesisiran \\ Kelurahan Kutorejo}

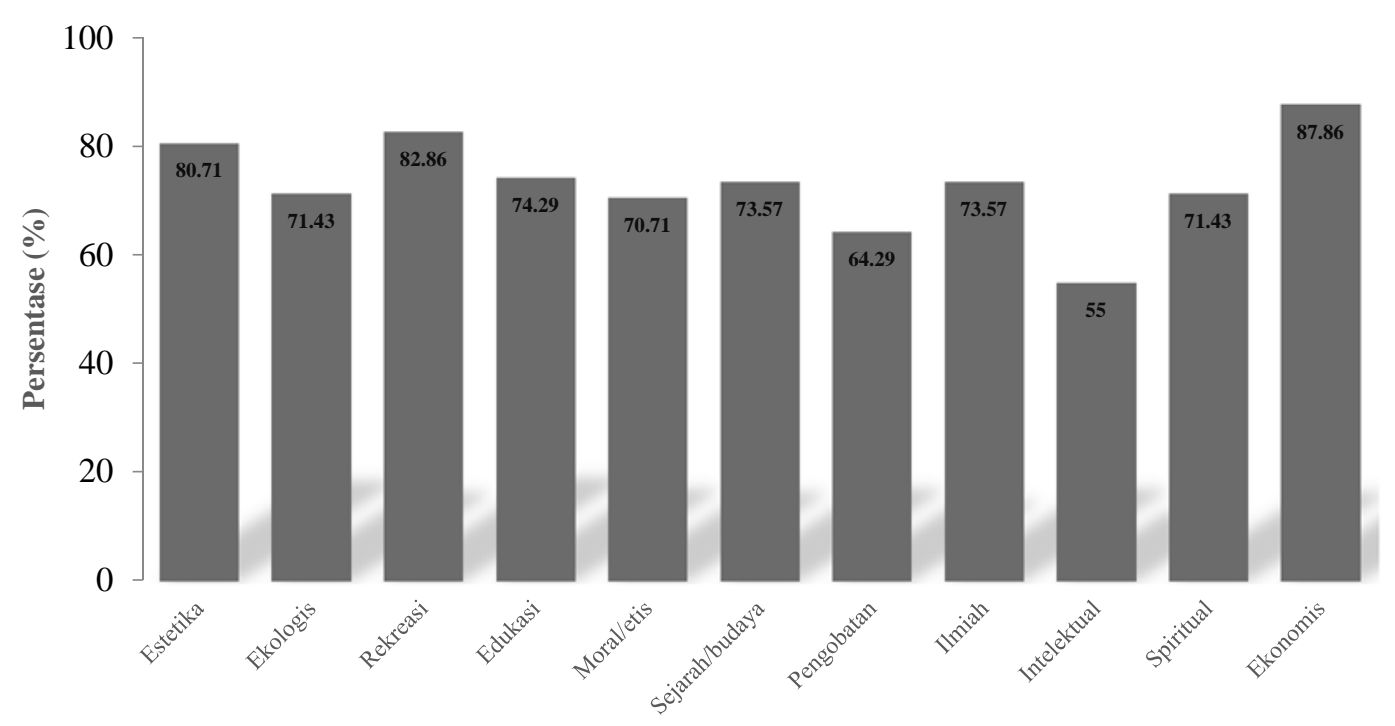

Gambar 7.

Nilai Wilayah Kepesisiran Kutorejo

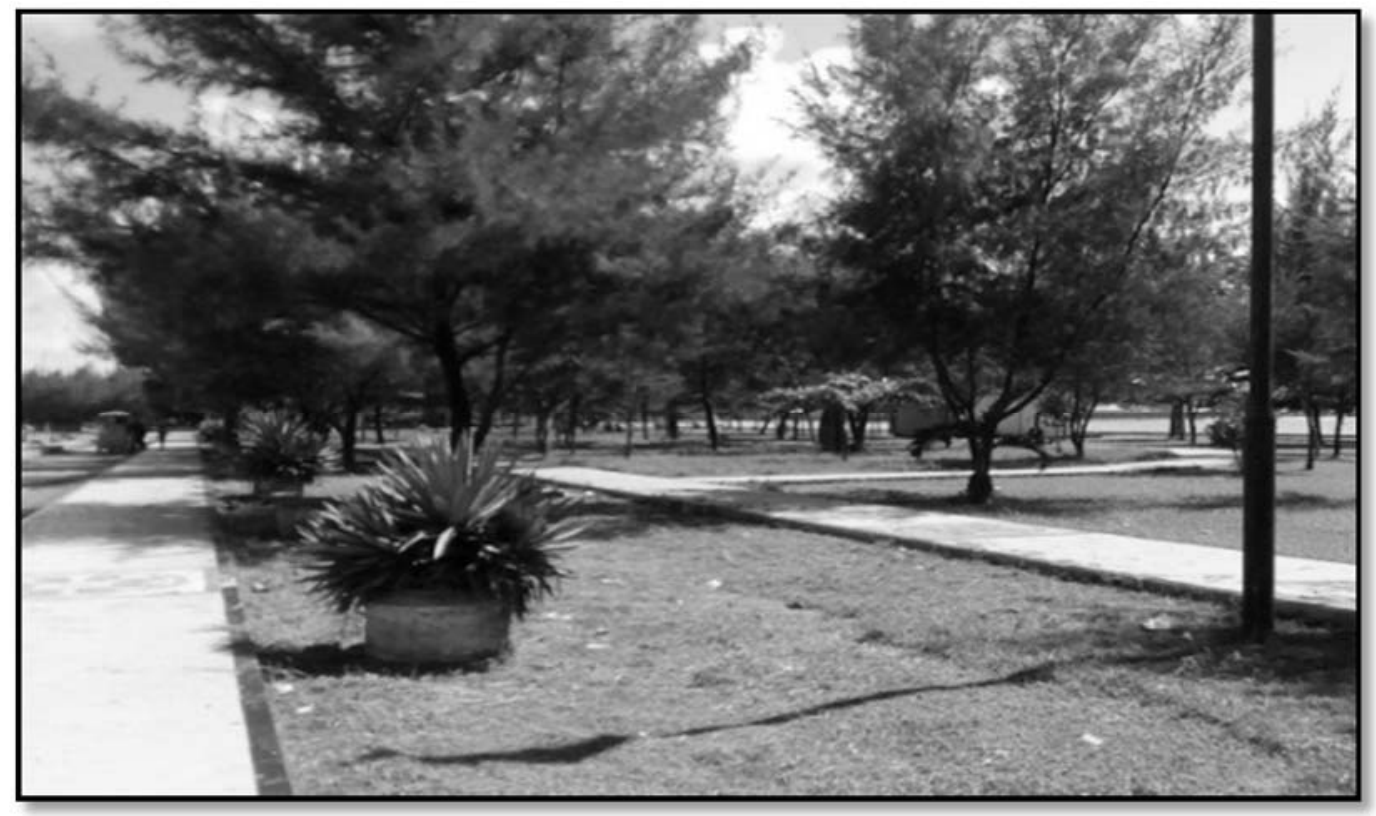

Gambar 8.

Wisata Pantai Boom di Kutorejo

Berdasarkan grafik di atas, diketahui bahwa nilai wilayah kepesisiran Kutorejo yang paling tinggi $(87,86 \%)$ yaitu nilai ekonomis dan nilai yang paling rendah (55\%) yaitu nilai intelektual. Hasil pengamatan di lapangan, wilayah kepesisiran Kutorejo dimanfaatkan sebagai wisata pantai.

\subsection{Nilai Etika Lingkungan Masyarakat di Wilayah Kepesisiran Tuban}

Nilai etika lingkungan masyarakat di wilayah kepesisiran Tuban meliputi tiga komponen, yaitu Spiritual Intelligence (SI),Intelligence Quotient (IQ), dan Emotional Intelligence (EI). Spiritual Intelligence mencakup pengetahuan keagamaan dan hal-hal yang diyakini oleh 
seseorang. Intelligence Quotient mencakup pengetahuan yang berkaitan dengan lingkungan sekitar. Emotional Intelligence mencakup perasaan seseorang dalam menanggapi hal-hal yang terjadi di lingkungan sekitar.

Tabel 2. Nilai Spiritual Intelligence di empat desa/kelurahan penelitian

\begin{tabular}{|c|c|c|c|c|c|}
\hline \multirow{2}{*}{ No } & \multirow{2}{*}{ Pernyataan } & \multicolumn{4}{|c|}{ Nilai Spiritual Intelligence (\%) } \\
\hline & & Karangagung & Panyuran & Sukolilo & Kutorejo \\
\hline 1 & Kebersihan sebagian dari iman & $\begin{array}{l}81,43 \\
\text { (SS) }\end{array}$ & $\begin{array}{c}87,14 \\
\text { (SS) }\end{array}$ & $\begin{array}{c}86,43 \\
(\mathrm{SS})\end{array}$ & $\begin{array}{c}87,86 \\
(\mathrm{SS})\end{array}$ \\
\hline 2 & $\begin{array}{l}\text { Saling berbuat baik dan tolong menolong } \\
\text { dalam hal kebaikan }\end{array}$ & $\begin{array}{l}78,57 \\
(\mathrm{SS})\end{array}$ & $\begin{array}{l}85,00 \\
(\mathrm{SS})\end{array}$ & $\begin{array}{l}93,57 \\
(\mathrm{SS})\end{array}$ & $\begin{array}{l}89,29 \\
(\mathrm{SS})\end{array}$ \\
\hline 3 & $\begin{array}{l}\text { Manusia sebagai khalifah yang } \\
\text { memelihara bumi }\end{array}$ & $\begin{array}{l}80,00 \\
(S)\end{array}$ & $\begin{array}{l}85,71 \\
(\mathrm{SS})\end{array}$ & $\begin{array}{c}85,00 \\
(\mathrm{SS})\end{array}$ & $\begin{array}{l}86,43 \\
(\mathrm{SS})\end{array}$ \\
\hline 4 & $\begin{array}{l}\text { Tidak menyakiti hewan karena makhluk } \\
\text { ciptaan Tuhan }\end{array}$ & $\begin{array}{l}72,14 \\
(S)\end{array}$ & $\begin{array}{l}75,00 \\
(S)\end{array}$ & $\begin{array}{l}77,14 \\
(S)\end{array}$ & $\begin{array}{l}79,29 \\
(S)\end{array}$ \\
\hline 5 & $\begin{array}{l}\text { Tumbuhan makhluk ciptaan Tuhan dijaga } \\
\text { kelestariannya }\end{array}$ & $\begin{array}{c}82,14 \\
(\mathrm{SS})\end{array}$ & $\begin{array}{c}87,86 \\
(\mathrm{SS})\end{array}$ & $\begin{array}{c}85,71 \\
(\mathrm{SS})\end{array}$ & $\begin{array}{c}86,43 \\
(\mathrm{SS})\end{array}$ \\
\hline & Rata-rata & $\begin{array}{l}78,86 \\
(S)\end{array}$ & $\begin{array}{c}84,14 \\
(\mathrm{SS})\end{array}$ & $\begin{array}{l}85,57 \\
(\mathrm{SS})\end{array}$ & $\begin{array}{l}85,86 \\
(\mathrm{SS})\end{array}$ \\
\hline
\end{tabular}

Keterangan: SS = Sangat Setuju; S = Setuju

Sumber: Hasil Pengolahan Data, 2018

Tabel 3. Nilai Intelligence Quotient di empat desa/kelurahan penelitian

\begin{tabular}{|c|c|c|c|c|c|}
\hline \multirow{2}{*}{ No } & \multirow{2}{*}{ Pernyataan } & \multicolumn{4}{|c|}{ Nilai Intelligence Quotient (\%) } \\
\hline & & Karangagung & Panyuran & Sukolilo & Kutorejo \\
\hline 1 & Sampah harus dibuang pada tempatnya & $\begin{array}{l}75,71 \\
(S)\end{array}$ & $\begin{array}{c}83,57 \\
\text { (SS) }\end{array}$ & $\begin{array}{c}85,00 \\
\text { (SS) }\end{array}$ & $\begin{array}{c}95,00 \\
\text { (SS) }\end{array}$ \\
\hline 2 & $\begin{array}{l}\text { Sampah yang dibuang di laut } \\
\text { menyebabkan pencemaran }\end{array}$ & $\begin{array}{l}77,14 \\
(S)\end{array}$ & $\begin{array}{l}84,29 \\
(\mathrm{SS})\end{array}$ & $\begin{array}{l}85,71 \\
\text { (SS) }\end{array}$ & $\begin{array}{c}96,43 \\
\text { (SS) }\end{array}$ \\
\hline 3 & $\begin{array}{l}\text { Sampah yang berserakan di pantai akan } \\
\text { merusak keindahan }\end{array}$ & $\begin{array}{l}77,14 \\
(S)\end{array}$ & $\begin{array}{l}84,29 \\
(\mathrm{SS})\end{array}$ & $\begin{array}{c}85,71 \\
(\mathrm{SS})\end{array}$ & $\begin{array}{c}96,43 \\
(\mathrm{SS})\end{array}$ \\
\hline 4 & $\begin{array}{l}\text { Mangrove dan tanaman pantai penting } \\
\text { untuk melindungi pantai dan meredam } \\
\text { ombak }\end{array}$ & $\begin{array}{l}77,14 \\
(S)\end{array}$ & $\begin{array}{l}85,71 \\
(\mathrm{SS})\end{array}$ & $\begin{array}{c}87,86 \\
(\mathrm{SS})\end{array}$ & $\begin{array}{c}84,29 \\
(\mathrm{SS})\end{array}$ \\
\hline 5 & $\begin{array}{l}\text { Terumbu karang penting untuk habitat } \\
\text { ikan }\end{array}$ & $\begin{array}{l}90,00 \\
(\mathrm{SS})\end{array}$ & $\begin{array}{l}88,57 \\
(\mathrm{SS})\end{array}$ & $\begin{array}{l}76,43 \\
(S)\end{array}$ & $\begin{array}{l}74,29 \\
(S)\end{array}$ \\
\hline 6 & $\begin{array}{l}\text { Penggunaan pukat harimau mengakibatkan } \\
\text { overfishing karena ikan kecil ikut terjaring }\end{array}$ & $\begin{array}{l}86,43 \\
(\mathrm{SS})\end{array}$ & $\begin{array}{c}85,71 \\
(\mathrm{SS})\end{array}$ & $\begin{array}{l}82,86 \\
(\mathrm{SS})\end{array}$ & $\begin{array}{c}81,43 \\
(\mathrm{SS})\end{array}$ \\
\hline 7 & $\begin{array}{l}\text { Penggunaan bom dan racun menimbulkan } \\
\text { kerusakan terumbu karang dan ikan kecil } \\
\text { mati }\end{array}$ & $\begin{array}{c}88,57 \\
(\mathrm{SS})\end{array}$ & $\begin{array}{l}87,14 \\
(\mathrm{SS})\end{array}$ & $\begin{array}{c}85,00 \\
(\mathrm{SS})\end{array}$ & $\begin{array}{l}82,86 \\
(\mathrm{SS})\end{array}$ \\
\hline 8 & $\begin{array}{l}\text { Industri di pesisir berpotensi menimbulkan } \\
\text { pencemaran }\end{array}$ & $\begin{array}{l}85,71 \\
(\mathrm{SS})\end{array}$ & $\begin{array}{l}88,57 \\
(\mathrm{SS})\end{array}$ & $\begin{array}{l}91,43 \\
(\mathrm{SS})\end{array}$ & $\begin{array}{l}95,71 \\
(\mathrm{SS})\end{array}$ \\
\hline 9 & $\begin{array}{l}\text { Limbah industri harus diolah dahulu } \\
\text { sebelum dibuang ke laut }\end{array}$ & $\begin{array}{c}86,43 \\
(\mathrm{SS})\end{array}$ & $\begin{array}{l}89,29 \\
(\mathrm{SS})\end{array}$ & $\begin{array}{l}92,86 \\
(\mathrm{SS})\end{array}$ & $\begin{array}{c}96,43 \\
(\mathrm{SS})\end{array}$ \\
\hline 10 & $\begin{array}{l}\text { Limbah industri yang langsung dibuang ke } \\
\text { laut menyebabkan pencemaran laut }\end{array}$ & $\begin{array}{c}85,00 \\
(\mathrm{SS})\end{array}$ & $\begin{array}{c}88,57 \\
(\mathrm{SS})\end{array}$ & $\begin{array}{l}91,43 \\
(\mathrm{SS})\end{array}$ & $\begin{array}{c}95,71 \\
(\mathrm{SS})\end{array}$ \\
\hline & Rata-rata & $\begin{array}{c}82,93 \\
(\mathrm{SS})\end{array}$ & $\begin{array}{c}86,57 \\
\text { (SS) }\end{array}$ & $\begin{array}{c}86,43 \\
(\mathrm{SS})\end{array}$ & $\begin{array}{c}89,86 \\
\text { (SS) }\end{array}$ \\
\hline
\end{tabular}

Keterangan: SS = Sangat Setuju; S = Setuju

Sumber: Hasil Pengolahan Data, 2018 
Tabel 4. Nilai Emotional Intelligence di empat desa/kelurahan penelitian

\begin{tabular}{|c|c|c|c|c|c|}
\hline \multirow{2}{*}{ No } & \multirow{2}{*}{ Pernyataan } & \multicolumn{4}{|c|}{ Nilai Emotional Intelligence (\%) } \\
\hline & & Karangagung & Panyuran & Sukolilo & Kutorejo \\
\hline 1 & $\begin{array}{l}\text { Anda melihat rumah dan lingkungan } \\
\text { sekitar kotor }\end{array}$ & $\begin{array}{l}85,00 \\
\text { (STS) }\end{array}$ & $\begin{array}{l}92,86 \\
\text { (STS) }\end{array}$ & $\begin{array}{l}94,29 \\
\text { (STS) }\end{array}$ & $\begin{array}{l}92,14 \\
\text { (STS) }\end{array}$ \\
\hline 2 & Anda melihat pantai kotor karena sampah & $\begin{array}{l}83,57 \\
\text { (STS) }\end{array}$ & $\begin{array}{l}85,71 \\
\text { (STS) }\end{array}$ & $\begin{array}{l}88,57 \\
\text { (STS) }\end{array}$ & $\begin{array}{l}95,71 \\
\text { (STS) }\end{array}$ \\
\hline 3 & $\begin{array}{l}\text { Anda melihat orang membuang sampah di } \\
\text { pantai }\end{array}$ & $\begin{array}{l}77,14 \\
(\mathrm{TS})\end{array}$ & $\begin{array}{l}84,29 \\
(\mathrm{STS})\end{array}$ & $\begin{array}{l}85,71 \\
\text { (STS) }\end{array}$ & $\begin{array}{l}96,43 \\
\text { (STS) }\end{array}$ \\
\hline 4 & $\begin{array}{l}\text { Anda melihat orang membuang hajat di } \\
\text { pantai }\end{array}$ & $\begin{array}{l}65,71 \\
(\mathrm{TS})\end{array}$ & $\begin{array}{l}74,29 \\
(\mathrm{TS})\end{array}$ & $\begin{array}{l}90,71 \\
\text { (STS) }\end{array}$ & $\begin{array}{l}95,00 \\
\text { (STS) }\end{array}$ \\
\hline 5 & Anda melihat orang menebang mangrove & $\begin{array}{l}67,86 \\
(\mathrm{TS})\end{array}$ & $\begin{array}{l}79,29 \\
\text { (STS) }\end{array}$ & $\begin{array}{l}83,57 \\
\text { (STS) }\end{array}$ & $\begin{array}{l}82,14 \\
\text { (STS) }\end{array}$ \\
\hline 6 & $\begin{array}{l}\text { Anda melihat orang menangkap ikan } \\
\text { dengan pukat harimau/racun/bom }\end{array}$ & $\begin{array}{l}88,57 \\
\text { (STS) }\end{array}$ & $\begin{array}{l}87,14 \\
\text { (STS) }\end{array}$ & $\begin{array}{l}85,00 \\
\text { (STS) }\end{array}$ & $\begin{array}{l}82,86 \\
\text { (STS) }\end{array}$ \\
\hline 7 & $\begin{array}{l}\text { Anda melihat alih fungsi lahan dari } \\
\text { mangrove/tambak menjadi industri }\end{array}$ & $\begin{array}{l}77,86 \\
\text { (TS) }\end{array}$ & $\begin{array}{l}83,57 \\
\text { (STS) }\end{array}$ & $\begin{array}{l}83,57 \\
\text { (STS) }\end{array}$ & $\begin{array}{l}83,57 \\
\text { (STS) }\end{array}$ \\
\hline 8 & $\begin{array}{l}\text { Anda melihat reklamasi pantai untuk } \\
\text { pembangunan industri, } \begin{array}{l}\text { wisata, dan } \\
\text { permukiman }\end{array}\end{array}$ & $\begin{array}{l}72,14 \\
\text { (TS) }\end{array}$ & $\begin{array}{l}77,86 \\
\text { (TS) }\end{array}$ & $\begin{array}{l}77,86 \\
\text { (TS) }\end{array}$ & $\begin{array}{l}80,71 \\
(\mathrm{STS})\end{array}$ \\
\hline 9 & $\begin{array}{l}\text { Anda melihat banyak industri di sepanjang } \\
\text { pesisir }\end{array}$ & $\begin{array}{l}85,71 \\
\text { (STS) }\end{array}$ & $\begin{array}{l}88,57 \\
\text { (STS) }\end{array}$ & $\begin{array}{l}91,43 \\
\text { (STS) }\end{array}$ & $\begin{array}{l}95,71 \\
\text { (STS) }\end{array}$ \\
\hline 10 & $\begin{array}{l}\text { Anda melihat limbah industri yang } \\
\text { dibuang langsung ke laut }\end{array}$ & $\begin{array}{l}86,43 \\
\text { (STS) }\end{array}$ & $\begin{array}{l}89,29 \\
\text { (STS) }\end{array}$ & $\begin{array}{l}92,86 \\
\text { (STS) }\end{array}$ & $\begin{array}{l}95,71 \\
\text { (STS) }\end{array}$ \\
\hline & Rata-rata & $\begin{array}{l}79,00 \\
\text { (TS) }\end{array}$ & $\begin{array}{l}84,29 \\
\text { (STS) }\end{array}$ & $\begin{array}{l}87,36 \\
\text { (STS) }\end{array}$ & $\begin{array}{l}90,00 \\
\text { (STS) }\end{array}$ \\
\hline
\end{tabular}

Keterangan: STS = Sangat Tidak Senang; TS = Tidak Senang

Sumber: Hasil Pengolahan Data, 2018

\subsection{Etika Lingkungan Kepesisiran Tuban}

\section{berdasarkan Nilai Wilayah Kepesisiran}

Penerapan etika lingkungan dalam pengelolaan wilayah kepesisiran sangat penting. Etika lingkungan tidak hanya mengimbangi hak dan kewajiban terhadap lingkungan, tetapi juga membatasi tingkah laku dan mengendalikan berbagai kegiatan agar tetap berada dalam batas kelentingan lingkungan. Etika lingkungan memberikan dampak positif untuk kesadaran moral, tanggung jawab, dan mengatur perilaku manusia terhadap lingkungan, sehingga manusia merasa mempunyai peran aktif terhadap lingkungannya. Etika lingkungan dalam pengelolaan wilayah kepesisiran Tuban dirumuskan berdasarkan nilai wilayah kepesisiran Tuban yang mencakup 11 aspek.

Tabel 5.Etika Lingkungan Pengelolaan Wilayah Kepesisiran di empat desa/kelurahan penelitian

\begin{tabular}{|c|c|c|}
\hline No & Nilai & Etika Lingkungan Kepesisiran Tuban \\
\hline 1 & Estetika & $\begin{array}{l}\text { Penjagaan kebersihan wilayah kepesisiran dengan pembuatan aturan tegas } \\
\text { untuk tidak membuang sampah di pantai }\end{array}$ \\
\hline 2 & Ekologis & $\begin{array}{l}\text { Penanaman sempadan pantai seperti mangrove, cemara, dan tanaman pantai } \\
\text { lainnya }\end{array}$ \\
\hline 3 & Rekreasi & $\begin{array}{l}\text { Pengembangan wisata pantai untuk berenang, naik perahu, dan aktivitas } \\
\text { rekreasi lainnya }\end{array}$ \\
\hline & & Pengembangan wisata religi seperti makam bersejarah \\
\hline 4 & Edukasi & Pengembangan ekowisata pantai seperti ekowisata mangrove \\
\hline 5 & Moral/etis & Pelestarian flora dan fauna endemik wilayah kepesisiran \\
\hline & & $\begin{array}{l}\text { Perlindungan wilayah kepesisiran terhadap segala aktivitas perusakan dan } \\
\text { pencemaran }\end{array}$ \\
\hline 6 & Sejarah/budaya & Pelestarian budaya pesisir seperti petik laut \\
\hline
\end{tabular}




\begin{tabular}{|c|c|c|}
\hline No & Nilai & Etika Lingkungan Kepesisiran Tuban \\
\hline & & Pemberian papan informasi nilai sejarah yang ada di lokasi wisata \\
\hline 7 & Pengobatan & $\begin{array}{l}\text { Pelestarian wilayah kepesisiran dengan menjaga agar selalu hijau dan bersih } \\
\text { dari sampah sehingga orang yang sedang penat karena pekerjaan atau hal lain } \\
\text { dapat merasa segar kembali baik jasmani (fisik) atau rohani melalui kontak } \\
\text { dengan alam }\end{array}$ \\
\hline 8 & Ilmiah & $\begin{array}{l}\text { Penelitian potensi bawah laut dan potensi lain di wilayah kepesisiran yang } \\
\text { kemungkinan belum pernah diteliti sebelumnya }\end{array}$ \\
\hline 9 & Intelektual & $\begin{array}{l}\text { Pengembangan ekowisata pantai dan pelestarian wilayah kepesisiran untuk } \\
\text { mendorong berpikir kreatif dan terinspirasi alam }\end{array}$ \\
\hline 10 & Spiritual & $\begin{array}{l}\text { Pelestarian wilayah kepesisiran dari segala aktivitas perusakan dan pencemaran } \\
\text { agar ketika seseorang yang sedang berada di pantai untuk merenung dapat } \\
\text { merasa lebih dekat kepada Tuhan atau memperoleh pengalaman spiritual lain } \\
\text { melalui kontak dengan alam seperti mengagumi alam ciptaanNya yang begitu } \\
\text { indah }\end{array}$ \\
\hline \multirow[t]{2}{*}{11} & Ekonomis & $\begin{array}{l}\text { Penindakan tegas apabila ada yang melakukan perusakan atau pencemaran } \\
\text { terhadap sumberdaya pesisir seperti penggunaan bom/pukat harimau/racun } \\
\text { dalam menangkap ikan }\end{array}$ \\
\hline & & $\begin{array}{l}\text { Pemanfaatan sumberdaya pesisir tidak boleh berlebihan, harus memerhatikan } \\
\text { kelangsungan jangka panjang }\end{array}$ \\
\hline
\end{tabular}

Sumber: Hasil Analisis Data, 2018

\section{SIMPULAN}

Nilai wilayah kepesisiran Tuban meliputi estetika, ekologis, rekreasi, edukasi, moral/etis, sejarah/budaya, pengobatan, ilmiah, intelektual, spiritual, dan ekonomis. Nilai wilayah kepesisiran Karangagung yang paling tinggi yaitu nilai ekonomis dan nilai yang paling rendah yaitu nilai estetika. Nilai wilayah kepesisiran Panyuran sama seperti nilai wilayah kepesisiran Sukolilo, nilai yang paling tinggi yaitu nilai ekonomis dan nilai yang paling rendah yaitu nilai sejarah/budaya. Nilai wilayah kepesisiran Kutorejo yang paling tinggi yaitu nilai ekonomis dan nilai yang paling rendah yaitu nilai intelektual.

Nilai etika lingkungan masyarakat di wilayah kepesisiran Tuban meliputi nilai Spiritual Intelligence,Intelligence Quotient, danEmotional Intelligence. Nilai Spiritual Intelligence, Intelligence Quotient, dan Emotional Intelligence paling tinggi di Kelurahan Kutorejo. Nilai Spiritual Intelligence, Intelligence Quotient, dan Emotional Intelligence paling rendah di Desa Karangagung.

Etika lingkungan kepesisiran Tuban berdasarkan nilai wilayah kepesisiran meliputi penjagaan kebersihan wilayah kepesisiran, penanaman sempadan pantai, pengembangan wisata pantai untuk berenang, naik perahu, dan aktivitas rekreasi lainnya, pengembangan wisata religi, pengembangan ekowisata pantai, pelestarian flora dan fauna endemik wilayah kepesisiran, perlindungan wilayah kepesisiran terhadap segala aktivitas perusakan dan pencemaran, pelestarian budaya pesisir, pemberian papan informasi nilai sejarah yang ada di lokasi wisata, pelestarian wilayah kepesisiran agar selalu hijau dan bersih dari sampah, penelitian potensi bawah laut dan potensi lain di wilayah kepesisiran, penindakan tegas terhadap perusakan atau pencemaran sumberdaya pesisir, pemanfaatan sumberdaya pesisir harus memerhatikan kelangsungan jangka panjang.

Etika lingkungan yang baik sangat diperlukan untuk keberlanjutan lingkungan hidup baik bagi manusia, hewan, dan tumbuhan. Untuk itu, diperlukan kesadaran yang dimulai dari diri sendiri agar selalu berperilaku mencintai lingkungan sekitar.

\section{DAFTAR PUSTAKA}

Anonim. 2014. Buku Ajar MKU: Pendidikan Lingkungan Hidup. Semarang: Tim MKU PLH Universitas Negeri Semarang.

Azwar, S. 2009. Metode Penelitian. Yogyakarta: Pustaka Pelajar. 
Clark, J.R. 1996. Coastal Zone Management Handbook. New York: Lewis Publisher.

Hartomo, W. 2004. Perencanaan Pengelolaan Sumberdaya Pesisir secara Terpadu dalam Menunjang Pembangunan Daerah. Makalah. Bogor: Institut Pertanian Bogor.

Idris, I. 2001. Kebijakan Pengelolaan Pesisir Terpadu di Indonesia. Jakarta: Graha Sucofindo.

Keraf, A. S. 2010. Etika Lingkungan Hidup. Jakarta: Kompas.

Manning, R., Valliere, W., dan Minteer, W. 1999. Values, Ethics, and Attitudes TowardNational Forest Management: An Empirical Study. Society and Natural Resources, 12: 421-436.
Pagoray, H. 2003. Lingkungan Pesisir dan Masalahnya sebagai Daerah Aliran Buangan Limbah. Makalah. Bogor: Institut Pertanian Bogor.

Soemiarno, S., Kartono, H., dan Purbaningsih, S. 2010. Buku Ajar III: Bangsa, Budaya, dan Lingkungan Hidup di Indonesia. Jakarta: Badan Penerbit FK UI.

Wiryono. 2012. Pengantar Ilmu Lingkungan. Bengkulu: Badan Penerbitan Fakultas Pertanian UNIB.

Widoyoko, E.P. 2016. Teknik Penyusunan Instrumen Penelitian. Yogyakarta: Pustaka Pelajar. 